\title{
Diagnosing undernutrition children and adults: new French criteria. Why, for what and for whom? A joint statement of the French National Authority for Health and French Federation of Nutrition
}

Jacques Delarue $^{1 *}$, Jean-Claude Desport ${ }^{2}$, Béatrice Dubern ${ }^{3}$, Francisca Joly ${ }^{4}$, Emmanuel Mas $^{5}$, Alexandre Pitard ${ }^{6}$, Eric Fontaine ${ }^{7}$ and HAS Working Group ${ }^{8}$

${ }^{1}$ Department of Nutritional Sciences, University Hospital/Faculty of Medicine, University of Brest, Brest, France

${ }^{2}$ University Hospital, School of Medicine/Inserm U1094 NET, Limoges, France

${ }^{3}$ Nutrition et Gastroentérologie Pédiatriques, Hôpital Trousseau, AP-HP, INSERM Nutriomics, Sorbonne University, Paris,

France

${ }^{4}$ Service de gastroentérologie, MICI et Assistance Nutritive, Hôpital Beaujon, AP-HP, Inserm UMR1149, Université de Paris, Paris, France

${ }^{5}$ Unité de Gastroentérologie, Hépatologie, Nutrition, Diabétologie et Maladies Héréditaires du Métabolisme, Hôpital des Enfants, CHU de Toulouse, and IRSD, Toulouse University, INSERM, INRA, ENVT, UPS, Toulouse, France

${ }^{6}$ French National Authority for Health, Clinical Practice Guideline Department, Saint-Denis, France

${ }^{7}$ Grenoble University Hospital, Univ. Grenoble Alpes, INSERM, LBFA, Grenoble, France

${ }^{8}$ Frédéric Costes (Clermont-Ferrand), Marie-Laure De Botton (Lille), Anne Galinier (Toulouse), François Goldwasser (Paris), Bernard Grunberg (Miramas), Régis Hankard (Tours), Martine Le-Noc-Soudani (Paris); Yves Morel (Saint-Egrève), Agathe Raynaud-Simon (Paris); Florence Rossi Pacini (Marseille), Marcel Ruetsch (Dessenheim), David Seguy (Lille), Marie-Paule Vasson (Clermont-Ferrand), Jean-Fabien Zazzo (Clamart) (FNA Working Group).

(Submitted 24 November 2020 - Final revision received 20 April 2021 - Accepted 29 April 2021 - First published online 7 May 2021)

Abstract

The objective was to establish new diagnostic criteria for undernutrition for the French population, concordant for children aged $<18$ years and adults aged $<70$ years, easy to use by health professionals and applicable whatever the situation (in and outpatients). A multi-disciplinary working and a reading group were involved. The procedure was divided into four phases: (1) systematic review and synthesis of the literature; (2) writing of the initial version of the guidelines; (3) reading and (4) finalisation. The literature search included international guidelines, meta-analyses, systematic reviews and randomised control trials from January 2007 to 31 July 2018. A two-step approach was selected: diagnosing undernutrition and then grading its severity. For diagnosis at least one phenotypic criterion associated with at least one aetiologic criterion were required for both children and adults. Phenotypic criteria for children were weight loss, Body Mass Index (BMI) < International Obesity Task Force curve 18.5, weight stagnation, reduction of muscle mass/function; for adults: weight loss, BMI $<18.5$ and reduction of muscle mass/function. Aetiological criteria for children and adults were reduction in dietary intake, reduced absorption and hypercatabolism. Phenotypic metrics were used in both children and adults for grading severity (moderate or severe). These new French recommendations integrate the proposals of recent international recommendations combining aetiologic with phenotypic criteria, but for the first time, they are concordant for children and adults. The WHO threshold of 18.5 for BMI was kept as phenotypic criteria because epidemiological data show an increased mortality for that threshold.

Keywords: Nutritional assessment: Undernutrition: BMI: Muscle function assessment

Undernutrition can be defined as 'the state of an organism in nutritional imbalance'; this imbalance is characterised by a negative energy and/or protein balance. The imbalance inherent in undernutrition leads to deleterious effects on tissues and/or the entire body ${ }^{(1-4)}$, with measurable changes in body function and/or composition associated with a worsening of the prognosis of the underlying disease ${ }^{(2,4)}$. Within the concept of undernutrition, most authors have long recognised two major forms: the form without oedema has been classically called marasmus and the form with oedema has been called kwashiorkor ${ }^{(5,6)}$. As

Abbreviation: GLIM, Global Leadership Initiative on Undernutrition.

* Corresponding author: Jacques Delarue, email jacques.delarue@univ-brest.fr 
summarised by Waterlow ${ }^{(7)}$, according to classical theory, kwashiorkor results from a protein deficiency with relatively adequate energy intake, whereas marasmus is caused by a global energy and protein deficiency. Note, however, that Gopalan et $a l .{ }^{(8)}$ proposed that the difference between marasmus and kwashiorkor could be explained by the child's ability (marasmus) or not (kwashiorkor) to adapt. Actually, as underlined by Briend in his report ${ }^{(9)}$, the true pathophysiology of kwashiorkor remains incompletely elucidated. In practice, undernutrition with oedema appears to be more severe than the form without oedema because of possible complications, particularly digestive disorders and infections ${ }^{(8)}$; adults may also be affected ${ }^{(8)}$. Thus, the term proteolytic undernutrition may be more appropriate today. More recently, the terms 'cachexia', 'sarcopenia' and 'fragility' have appeared. Cachexia is characterised by an involuntary loss of muscle mass in a context of excessive cytokine production as in cancer and heart failure ${ }^{(10-12)}$ associated with a worsening prognosis. Sarcopenia initially defined by loss of skeletal muscle mass and is currently characterised by loss of muscle mass associated with functional deterioration. Frailty is a concept that combines vulnerability and poor adaptability as well as low energy and protein reserves ${ }^{(13,14)}$.

In 2019, a group of experts in a consortium called the Global Leadership Initiative on Undernutrition (GLIM) published globally applicable recommendations for adults ${ }^{(15)}$. The main novelty was the combination of so-called phenotypic criteria with so-called aetiological criteria. The experts selected five criteria: involuntary weight loss, decrease in Body Mass Index (BMI), reduction in muscle mass, decrease in food intake or absorption and presence of disease/inflammation. The proposed diagnostic criteria combine at least one phenotypic and at least one aetiologic criterion. These recommendations were a very significant step forward mainly because they incorporate the notion of aetiological criteria such as an underlying disease associated with phenotypic criteria which were generally the only ones taken into consideration up to now. They also incorporate the importance of quantifying muscle mass. With regard to paediatric undernutrition, the most widely used classification system was that proposed by Waterlow ${ }^{(7)}$. He suggested that acute undernutrition (wasting) be defined independently of age using weight as a percentage of weight for height calculated from the 50th percentile of the Boston standard ${ }^{(16)}$ and chronic undernutrition (stunting) be defined by height for age again based on the Boston standard. Acute undernutrition and chronic undernutrition were divided into four stages. Then, other definitions have been $\operatorname{proposed}^{(17-20)}$. In 2013, the Pediatric Undernutrition Definitions Working Group ${ }^{(21)}$ indicated that five areas should be considered: anthropometric parameters, growth, chronicity of undernutrition, aetiology and pathogenesis and developmental/ functional outcomes. They classified undernutrition as acute or chronic with a threshold of 3 months duration for the latter, with or without a disease-related threshold for aetiology, the presence or absence of an inflammatory state and pathogenic mechanisms leading to suboptimal nutrient intake/absorption. They recommended that anthropometric measures be expressed as $z$-scores, as proposed by the $\mathrm{WHO}^{(17)}$. Their consensus statement for $2015^{(22)}$ recommended the use of the following indicators: food/ nutrient intake, assessment of energy and protein requirements, growth parameters, speed of weight gain, mid-upper arm circumference, grip strength, indirect measures replacing traditional anthropometric measures and documentation of Tanner stage. The experts proposed to use $z$-scores for the criteria of weight for height/length, BMI for age, length/height for age or mid-upper arm circumference is indicated. They define mild undernutrition as a $z$-score between -1 and $-1.9 \mathrm{SD}$, moderate undernutrition as a $z$-score between -2 and $-2 \cdot 9 \mathrm{SD}$ and severe undernutrition as a $z$-score $\leq 3 \mathrm{SD}$ for each indicator. This American group proposed that indicators of undernutrition, i.e. weight for height, BMI or height for age, be used with the WHO growth standards for children from birth to 2 years of age and the CDC growth charts for children aged 2-20 years $^{(18)}$.

In summary, in recent years, expert committees have proposed new recommendations for the diagnosis of undernutrition in adults and children. So why propose French recommendations now? For the following main reasons: (a) the previous French recommendations were obsolete and dated from 2003, with several inconsistencies; (b) we disagreed with the choice of the $20 \mathrm{~kg} / \mathrm{m}^{2}$ threshold proposed by GLIM as a phenotypic criterion for undernutrition in adults under 70 years of age; (c) we wanted the diagnostic criteria for undernutrition in children to be consistent with those for adults and (d) in all cases, we wanted the diagnosis criteria for adults and children to be easy to use in clinical practice.

\section{Methods}

Good practice guidelines are defined in the health field as 'methodically developed proposals to help the practitioner and the patient find the most appropriate care in given clinical circumstances'. These guidelines were then developed according to Haute Autorité de Santé (HAS) standards. The complete methodology is available in the HAS methodological guide available on its website (https://www.has-sante.fr/jcms/c_431294/fr/recomman dations-pour-la-pratique-clinique-rpc).

The clinical practice guidelines method is a rigorous method based on:

- participation of professionals;

- transparency, with the provision of a critical analysis of the literature; the essential points of the debates and decisions made by the members of the working group; notes and comments from the members of the reading group and the list of all the participants in the different groups.

- independence linked to the status of the HAS as an independent public scientific authority (Law of 13 August 2004 on health insurance, Title II, Chapter I bis, Article L. 161-37);

- independence of the groups from one another; the working and reading groups each have a specific role which they perform independently of one another;

- financial independence; public financing in the context of the HAS GPG;

- management of the interests declared by the experts of the working group, according to the procedure described in the HAS 'Guide on declaration of interests and management of conflicts of interest'. 
In the current study, the clinical practice guidelines method involved two groups: a working group and a reading group. Two project managers were in charge of coordinating all the work of the working group with the HAS project manager. The working group was composed of twenty-one professionals: four nutritionists, three paediatricians, three general practitioners, one biologist, one oncologist, one gastroenterologists, two geriatricians, one dietitian, one pharmacist, one intensive care anaesthetist, one nurse and a HAS project leader. The reading group was composed of thirty-four professionals concerned with the subject. Like the working group, this group was multidisciplinary and multi-professional. The procedure of the method is divided into four phases: (1) systematic review and synthesis of the literature; (2) writing of the initial version of the guidelines; (3) reading and (4) finalisation.

\section{Systematic review and literature synthesis phase}

The drafting of the evidence report was preceded by a phase of document search and critical analysis of the literature. The reviewers, the project managers, HAS project leader and scientific librarian participated in the creation of the document search strategy. The document search was systematic, hierarchical and structured.

A strategy was designed to search MEDLINE (National Library of Medicine, USA), The Cochrane Library (Wiley Interscience, USA), Science Direct (Elsevier) and the HTA (International Network of Agencies for Health Technology Assessment) database using the following search terms (MeSH terms and equivalent free text terms):

For children: (1) First step: 'Malnutrition/diagnosis'[Majr] OR 'Severe Acute Malnutrition/diagnosis'[Majr] OR 'Nutrition Assessment'[Majr] OR 'Child Nutrition Disorders/diagnosis'[Majr] OR 'Nutritional Status'[Majr] OR (Nutritional Or malnutrition Or malnourished OR undernutrition OR undernutrition OR undernourished OR under-nourished) [title] AND (Screen or screening or assessment or measuring OR evaluation Or diagnostic OR diagnosis OR detection Or criteria Or definition) [title] AND consensus OR guidance OR guide OR guidelines OR position paper OR recommendation* OR statement Field: Title; (2) Second step: 'Malnutrition/diagnosis'[Majr] OR 'Severe Acute Malnutrition/ diagnosis'[Majr] OR 'Nutrition Assessment'[Majr] OR 'Child Nutrition Disorders/diagnosis'[Majr] OR 'Nutritional Status'[Majr] OR (Nutritional Or malnutrition Or malnourished OR undernutrition OR undernutrition OR undernourished OR under-nourished) [title] AND (Screen or screening or assessment or measuring OR evaluation Or diagnostic OR diagnosis OR detection Or criteria Or definition) [title] AND 'Meta-Analysis as Topic'[Mesh] OR 'Meta-Analysis '[Publication Type] OR 'Review Literature as Topic'[Mesh] OR 'Meta-Analysis' OR 'Systematic Review' OR 'Literature Review' Or 'Quantitative Review' OR 'Pooled Analysis' [Title/Abstract]

For adults: (1) First step: 'Malnutrition'[MeSH Major Topic] OR 'Severe Acute Malnutrition'[MeSH Major Topic] OR 'Nutrition Assessment'[MeSH Major Topic] OR 'Nutritional Status'[MeSH Major Topic] OR (('Malnutrition'[Title] AND ('Or'[All Fields] AND 'malnourished'[Title])) OR 'undernutrition'[Title] OR 'undernutrition'[Title] OR 'undernourished'[Title]) AND Guideline* or Consensus OR guidance OR recommend *[title];
(2) Second step: 'Malnutrition'[MeSH Major Topic] OR 'Severe Acute Malnutrition'[MeSH Major Topic] OR 'Nutrition Assessment'[MeSH Major Topic] OR 'Nutritional Status'[MeSH Major Topic] OR (('Malnutrition'[Title] AND ('Or'[All Fields] AND 'malnourished'[Title])) OR 'undernutrition'[Title] OR 'undernutrition'[Title] OR 'undernourished'[Title]) AND 'MetaAnalysis as Topic'[Mesh] OR 'Meta-Analysis '[Publication Type] OR 'Review Literature as Topic'[Mesh] OR 'Meta-Analysis' OR 'systematic Review' OR 'Literature review' Or 'Quantitative Review' OR 'pooled analysis' [Title/Abstract].

The languages selected were English and French. The start date used was January 2007, and the last search date used was 31 July 2018. Several articles in the bibliography appeared to be published outside this period because (1) the search strategy has been updated regularly until the end of the project in 2019 and (2) the search strategy was supplemented by the bibliographic contribution of the experts of the working group and reading groups, and the references cited in the documents analysed. The literature search included international guidelines, meta-analyses, systematic reviews and randomised controlled trials.

The literature search was not limited to articles published and indexed in databases. For this, grey literature was found by consulting relevant sources. This search made it possible to initially identify the French and international guidelines and evidence reports created by governmental agencies, independent evaluation agencies and learned societies. French and international biomedical databases were queried. It was supplemented by the bibliographic contribution of the experts of the working group and reading groups, and the references cited in the documents analysed. The document search strategy appeared in the evidence report available on the HAS website: -https://www.has-sante.fr/ upload/docs/application/pdf/2019-11/reco277_argumentaire_ rbp_denutrition__cd_2019_11_13_v0.pdf. It describes the key words used as well as the types of documents searched in the databases, specifying the results obtained, and also states the sources used for searching grey literature.

A total of 1258 publications were identified. Three reviewers (JCD, FJ, EM) reviewed all titles and selected studies based on titles and/or abstracts. Studies that met the defined inclusion criteria were selected for article review. If it was not clear from the abstract whether a study met the inclusion criteria, the full article was reviewed.

The flow chart of literature screening is presented in Fig. 1. The reviewers conducted a critical analysis and synthesis of the selected literature in the form of an evidence report and proposed a list of recommendations based on the literature review conducted. The proposed recommendations based on the critical review of the literature by the reviewers were sent to the members of the working group $15 \mathrm{~d}$ before the first meeting.

\section{Drafting of the initial version of the guidelines}

The members of the working group met for five one-day discussion sessions between April 2018 and January 2019, in order to create, on the basis of the evidence report and the proposed recommendations drafted by the reviewers, the initial version of the guidelines to be submitted to the reading group. The two project 

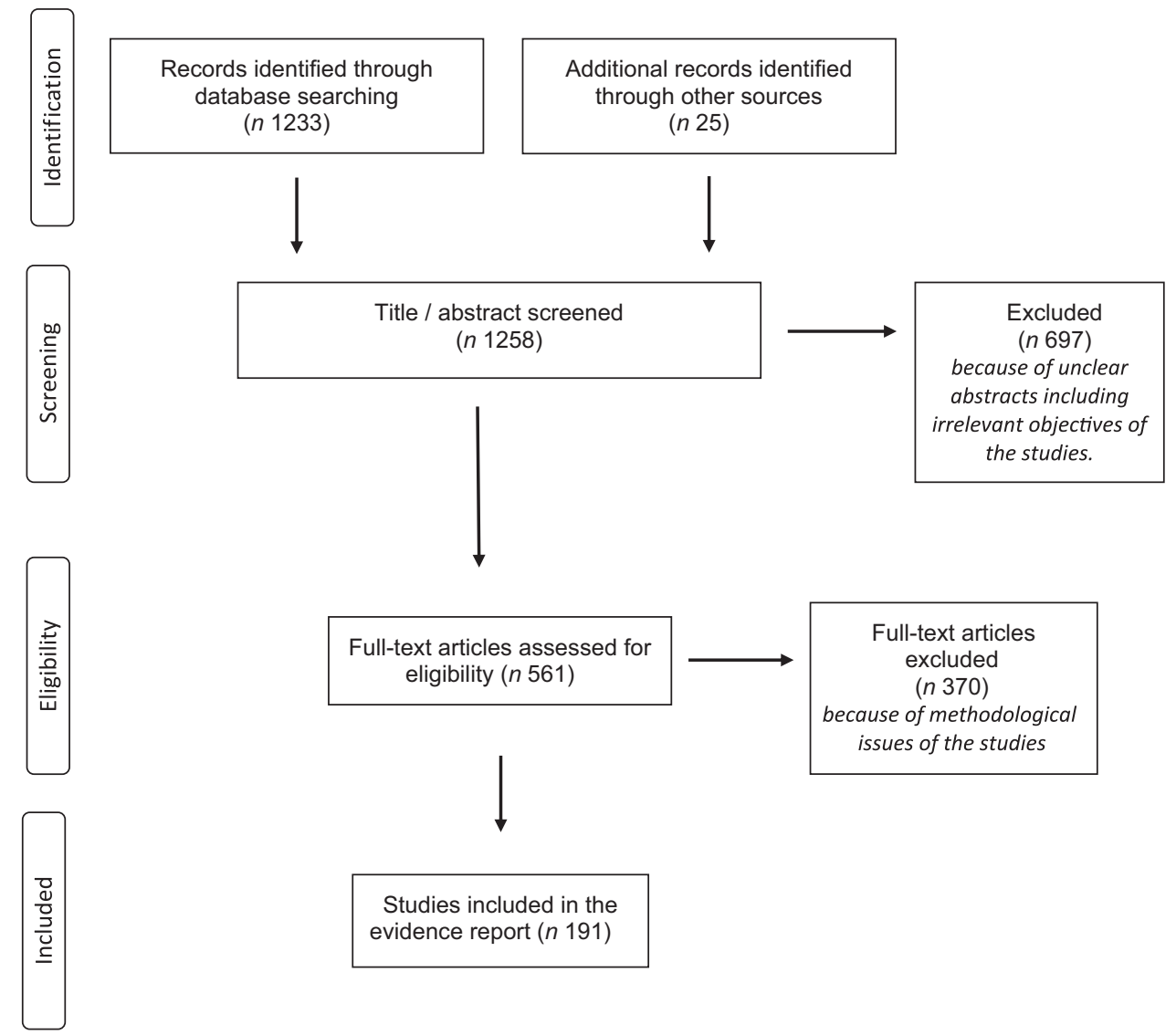

Studies included in the evidence report ( $n$ 191)

Fig. 1 Flow chart of literature screening.

leaders of the working group and the HAS project leader shared the responsibility for leading and facilitating the working group meetings. During the working group meetings, the evidence reports and proposed recommendations were discussed on the basis of existing data and practices. The majority of the recommendations were based on the agreement of the experts in the working group and were then referred to as 'expert consensus'. The members of the working group were appointed by HAS on the proposal of the parties concerned by the topic: national professional specialty councils, the Board of general medicine, professional organisations and institutions. For this guideline project, the working group included twenty-one French professionals from different specialties: nutrition, paediatrics, general medicine, oncology, gastroenterology, geriatrics, pharmacy, biology, nursing, and dietetics.

The composition of the experts group guaranteed a balanced representation of:

- main healthcare professions in accordance with the project outline;

- methods of practice (public, university-based or not and selfemployed);

- different currents of opinion or schools of thought;

- the geographical origins of the experts.
In general, the healthcare professionals of the group must have a good knowledge of professional practice in the field corresponding to the topic of the study and must be able to judge the relevance of the published studies and different clinical situations evaluated. The working group must bring together professionals concerned by the topic under consideration.

The absence of a rating does not mean that the guidelines are not relevant and useful, but should nevertheless prompt further study. They should apply to the majority of cases, sometimes with an adjustment on a case-by-case basis.

\section{Reading phase}

In March 2019, the HAS project leader sent the evidence report, the initial version of the guidelines and the questionnaire to the members of the reading group, upon which each member gave an individual opinion electronically (using the GRaAL computer tool, available on the HAS website www.has-sante.fr). The questionnaire includes a discrete numerical scale, ranked from 1 to 9 , and a free text area for each recommendation made. It allows each member of the reading group to judge the form and content of the initial version of the guidelines, as well as the acceptability, applicability and readability of each recommendation. The score ranges from 1 (Strong Disagree) to 9 (Strongly Agree). In order to 
Table 1. General recommendations for diagnosing undernutrition in children ( $<18$ years)

- Always screening for undernutrition at each consultation is recommended.

- Recording the nutritional assessment in any documents (health record booklet, personal medical record (PMR), report, staff meeting and letters to correspondents) is recommended.

- Undernutrition can only be diagnosed in the presence of at least: 1 phenotypic criterion and 1 aetiological criterion.

Table 2. Phenotypic and etiological criteria for diagnosing undernutrition in children ( $<18$ years)

Phenotypic criteria (at least one)

$\geq 5 \%$ weight loss in 1 month or $\geq 10 \%$ in 6 months or $\geq 10 \%$ compared with the usual weight before the start of the disease;

BMI < IOTF curve 18.5;

weight stagnation leading to a weight located 2 corridors below the usual corridor (weight curve) ${ }^{\dagger}$;

reduction in muscle mass and/or muscle function (when the standards and/or tools are available) $)^{\ddagger}$.

Aetiological criteria (at least one)

reduced dietary intake $\geq 50 \%$ for more than 1 week or any reduction in intake for more than 2 weeks compared with:

usual dietary consumption quantified

or to estimated protein-energy requirements

decrease in food assimilation or absorption ${ }^{\S}$

stress (hypercatabolism with or without inflammation)

acute disease or

underlying chronic disease or undergoing malignancy

* The International Obesity Task Force (IOTF)'s curves are those recommended by the National Nutrition Health Plan for monitoring children's BMI. However, the IOTF does not propose BMI curves before the age of 2. The IOTF's curves were extended by the 'AFPA -- CRESS/Inserm - CompuGroup Medical 2018' curves over this age range. Curves available on the website: https://cress-umr1153.fr/index.php/courbes-carnet-de-sante

† Usual corridor = child's usual or reference weight growth corridor for specific diseases (Down syndrome, myopathy, etc.).

$¥$ There are no validated methods for assessing muscle function in children. Various methods have been described, such as the distance covered in 7 min, but none of them has been validated as a criterion of undernutrition in children. For muscle mass, there is no consensus on the reference value of brachial perimeter or brachial circumference. Validation studies are therefore necessary.

$\S$ Reduced absorption should be considered in cases of chronic diarrhoea or extensive small bowel resection or in cases of biological stigma of maldigestion such as reduced fatsoluble vitamins plasma concentrations.

improve the final text, any rating below 5 should be accompanied by a commentary.

\section{Finalisation}

In May 2019, the final version of the guidelines was drafted at the last meeting of the working group. After analysis and discussion of the reading group's notes and comments, the initial recommendations were modified according to the following rules: a) when the Reading Group confirmed the appropriateness of the recommendation ( $\geq 90 \%$ of the Reading Group's answers within the range (5-9)), the recommendation is retained and the relevant comments are taken into account to improve the form; b) when the reading group is more broadly undecided or disagrees with the initial recommendation ( $<90 \%$ of the reading group's responses within the range (5-9)), the working group discusses the appropriateness of the comments and, if necessary, modifies the recommendation. If discussions in the meeting reveal divergent views, a vote in the working group session should confirm the withdrawal or final wording of the amended recommendation. Ten recommendations had then been modified. Finally, 191 publications were discussed in the Evidence Report. This last step involved the working group and the HAS validation bodies. The final versions of the Evidence Report, the recommendations and its synthesis were published in November 2019 on the HAS website (https://www.has-sante. fr/upload/docs/application/pdf/2019-11/reco277_argumentaire_ rbp_denutrition_cd_2019_11_13_v0.pdf).

\section{Results}

\section{General recommendations, criteria for diagnosing, assessing the severity and monitoring undernutrition in children ( $<18$ years)}

The general recommendations are reported in Table 1. Undernutrition should be screened at each consultation, recorded in any document and can only be diagnosed in the presence of at least 1 phenotypic criterion and 1 aetiological criterion. This diagnosis is compulsory first before judging its severity. The phenotypic criterion is based exclusively on non-biological criteria.

The phenotypic and aetiological criteria (one of each is sufficient) are reported in Table 2. Phenotypic criteria are weight loss, BMI $<18.5$ (IOTF curve), weight located two corridors below the usual corridor (weight curve) and reduction in muscle mass/function. Aetiologic criteria are reduced dietary intake, decrease in food assimilation or absorption and hypercatabolism with or without inflammation.

The assessment of body composition can be done by different methods depending on local possibilities. Absorptiometry is the reference method, but other techniques such as impedancemetry can be used. However, these are 20-year-old works that cannot currently be used as references and justify studies in children in France. Measurement of the brachial perimeter, recognised by the WHO, is another simple method for assessing muscle mass. However, the threshold defining undernutrition 
Table 3. Assessment of severity of undernutrition in children*

Criteria for moderate undernutrition (one is sufficient):

IOTF curve $17<\mathrm{BMI}<$ IOTF curve 18.5 ;

$\geq 5 \%$ weight loss in 1 month or $\geq 10 \%$ in 6 months or $\geq 10 \%$ as compared with the usual weight before the start of the disease;

weight stagnation leading to a weight located between two and three corridors below the usual corridor.

Criteria for severe undernutrition (one is sufficient):

$\mathrm{BMI} \leq \mathrm{IOTF}$ curve 17

$>10 \%$ weight loss in 1 month or $>15 \%$ in 6 months compared with the usual weight before the start of the disease;

weight stagnation leading to a weight located at least three corridors (representing three standard deviations) below the usual corridor;

change in height (with loss of at least one corridor compared with the usual height).

* When a single criterion for severe undernutrition is observed simultaneously with one or more criteria for moderate undernutrition, a diagnosis of severe undernutrition is recommended.

IOTF, International Obesity Task Force.

Table 4. Monitoring the change in nutritional status of children

Monitoring the change in nutritional status and adaptation of management of an undernourished child.

Adapting nutritional management of an undernourished child according to the level of severity, by ensuring especially that refeeding syndrome is prevented, is recommended

In outpatient care, systematically evaluating the nutritional status of an undernourished child in the month following the last assessment is recommended.

In the event of hospitalisation, reassessing the nutritional status of an undernourished child at least once a week is recommended.

Monitoring the change in nutritional status and adaptation of management of a non-undernourished child, but with a disease (i.e., at risk of malnutrition).

In outpatient care, reassessing the child's nutritional status at each consultation is recommended.

In the event of hospitalisation, reassessing the nutritional status on admission is recommended.

Table 5. General recommendations for diagnosing undernutrition in adults $(\geq 18$ to $<70$ years)

- Always screening for undernutrition at each consultation and on admission to hospital is recommended.

- Recording the nutritional assessment in any documents (health record booklet, personal medical record (PMR), report, staff meeting and letters to

correspondents) is recommended.

- Undernutrition can only be diagnosed in the presence of at least: 1 phenotypic criterion and 1 aetiological criterion.

remains debated as it varies according to the populations studied: $<115 \mathrm{~mm}$ between 6 and 60 months for the WHO or $<133$ mm between 6 and 60 months in the Asian population, which is known to have a lower corpulence. This does not allow recommendations to be made. The 6-minute walk test is probably the simplest and most reproducible, but no standard has yet been established in children and requires further study.

Albumin was not used as a diagnosis criterion, because it is not a reliable marker of undernutrition in children due to the variations related to other conditions, such as inflammatory syndrome or enteropathy. In kwashiorkor, hypoalbuminaemia is a marker of hypoproteinaemia and of the presence of oedemas. In marasmus, albumin may be normal.

Once diagnosis of undernutrition has been done, its severity must be assessed.

The assessment criteria of the severity of undernutrition are reported in Table 3. Criteria for moderate undernutrition (one is sufficient) are BMI $>17$ and $<18.5$ (IOTF curve), $\geq 5 \%$ weight loss in 1 month or $\geq 10 \%$ in 6 months or $\geq 10 \%$ as compared with the usual weight before the start of the disease, weight located two and three corridors below the usual corridor. Criteria for severe undernutrition (one is sufficient) are $\mathrm{BMI} \leq 17$ (IOTF curve), $>10 \%$ weight loss in 1 month or $>15 \%$ in 6 months compared with the usual weight before the start of the disease, weight located at least three corridors (representing three standard deviations) below the usual corridor, loss of height of at least one corridor compared with the usual height.

The monitoring of the changes in nutritional status of children is reported in Table 4. If undernourished, adapting nutritional care according to the level of severity, especially preventing refeeding syndrome; in outpatient care, systematically re-evaluating the nutritional status in the month following the last assessment; during hospitalisation, reassessing the nutritional status at least once a week is recommended. If not undernourished but with a disease (i.e., at risk of malnutrition) in outpatient care, reassessing the nutritional status at each consultation during hospitalisation on admission.

\section{General recommendations, criteria for diagnosing, assessing the severity and monitoring undernutrition in adults ( $\geq 18$ to $<70$ years)}

The general recommendations for diagnosing undernutrition in adults ( $\geq 18-<70$ years) are reported in Table 5 . Undernutrition should be screened at each consultation, recorded in any document and can only be diagnosed in the presence of at least 1 phenotypic criterion and 1 aetiological criterion. This diagnosis is compulsory first before judging its severity. The phenotypic criterion is based exclusively on non-biological criteria. 
Table 6. Phenotypic and aetiological criteria for diagnosing undernutrition in adults ( $\geq 18$ to $<70$ years)

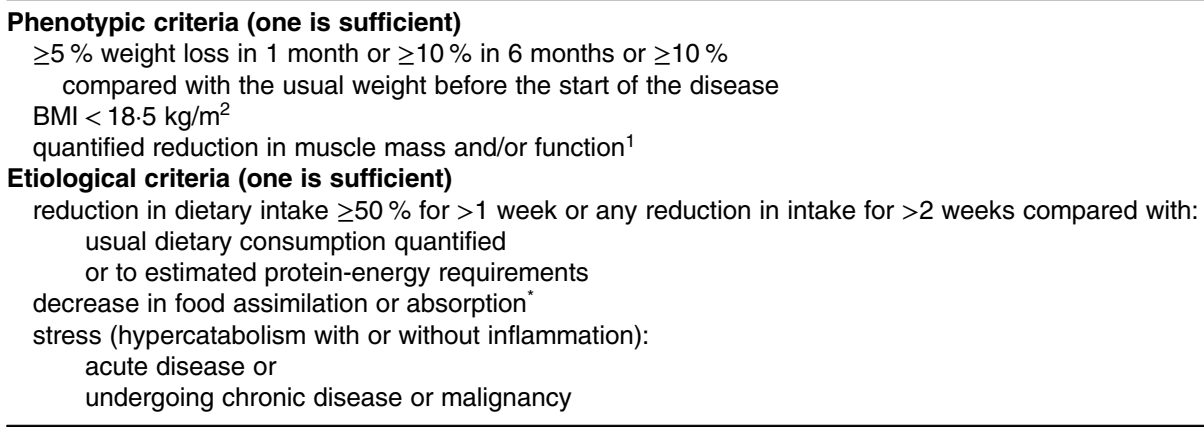

${ }^{*}$ Reduced absorption should be considered in cases of chronic diarrhea or extensive small bowel resection or in cases of biological stigma of maldigestion such as reduced fat-soluble vitamins plasma concentrations.

Table 7. Proposed methods and thresholds for the quantification of the reduction in muscle mass and/or function according to the most recently available data. References are in parenthesis

\begin{tabular}{lcc}
\hline Measurement methods & Men & Women \\
\hline Grip strength (dynamometer) in $\mathrm{kg}^{(55)}$ & $<26$ & $<16$ \\
Walking speed (m/s) $^{(55)}$ & $<0.8$ & $<0.8$ \\
Muscle surface area index in L3 in $\mathrm{cm}^{2} / \mathrm{m}^{2}$ (CT-scan, MRI-scan) $^{(56)}$ & 52.4 & 38.5 \\
Muscle mass index in $\mathrm{kg} / \mathrm{m}^{2}$ (impedance measurement) $^{(57)}$ & $7 \cdot 0$ & 5.7 \\
Non-fat mass index (impedance measurement) in $\mathrm{kg} / \mathrm{m}^{2(57)}$ & $<17$ & $<15$ \\
Appendix muscle mass (DEXA) in $\mathrm{kg} / \mathrm{m}^{2(57)}$ & 7.23 & 5.67 \\
\hline
\end{tabular}

The phenotypic and aetiological criteria (one of each is sufficient) are reported in Table 6 . Phenotypic criteria are weight loss, $\mathrm{BMI}<18 \cdot 5$, reduction in muscle mass/function. Aetiologic criteria are reduced dietary intake, decrease in food assimilation or absorption and hypercatabolism with or without inflammation.

The proposed methods and thresholds for the quantification of the reduction in muscle mass and/or function according to the most recently available data are reported in Table 7: grip strength (dynamometer), walking speed, muscle surface area index in L3 in $\mathrm{cm}^{2} / \mathrm{m}^{2}$ (CT-scan, MRI-scan), muscle mass index in $\mathrm{kg} / \mathrm{m}^{2}$ (impedance measurement), non-fat mass index (impedance measurement) in $\mathrm{kg} / \mathrm{m}^{2}$ and appendix muscle mass (DEXA) in $\mathrm{kg} / \mathrm{m}^{2}$.

Once diagnosis of undernutrition has been done, its severity must be assessed.

The assessment of the severity of undernutrition is reported in Table 8. Criteria for moderate undernutrition (one is sufficient) are BMI $>17$ and $<18 \cdot 5, \geq 5 \%$ weight loss in 1 month or $\geq 10 \%$ in 6 months or $\geq 10 \%$ as compared with the usual weight before the start of the disease, albuminaemia $>30 \mathrm{~g} / \mathrm{l}$ and $<35 \mathrm{~g} / \mathrm{l}$. Criteria for severe undernutrition (one is sufficient) are $\mathrm{BMI} \leq 17,>10 \%$ weight loss in 1 month or $>15 \%$ in 6 months compared with the usual weight before the start of the disease and albuminaemia $\leq 30 \mathrm{~g} / \mathrm{l}$.

The monitoring of the changes of nutritional status is reported in Table 9. If undernourished, adapt the nutritional care to the level of severity, preventing the refeeding syndrome. In outpatient care, assessing nutritional state within 3 months of the last assessment. If hospitalisation, reassessing at least once a week. In follow-up consultations after hospitalisation, systematically reassessing. If not undernourished, but with a disease (i.e., at risk of malnutrition) in ambulatory care, reassessing at each consultation. If inpatient care, reassessing on admission.

\section{Discussion}

These new French recommendations for diagnosis of undernutrition of both children and adults aged less 70 years were undertaken because previous adult French recommendations (published in 2003) ${ }^{(23)}$ needed to be revised for many objective reasons, among which: (a) there were no paediatric French recommendations; (b) we wanted a consistency between paediatric and adults; c) we disagreed with the choice of a BMI threshold of twenty proposed by the GLIM consortium even we recognised that their recommendations had several qualities. We will focus the discussion about the choice of the threshold of BMI, the significance of weight loss, the importance of the decrease in food intake, the true significance of plasma albumin concentrations and the consistency between children and adults' recommendations. The recommendations for adults $>70$ years of age first published in $2003^{(23)}$ were revised in $2007^{(24)}$ and are currently under new revision. For the sake of brevity, the GLIM criteria that we have retained will not be discussed below.

\section{Why did we choose a threshold of 18.5 for BMI as a phenotypic criterion?}

Before discussing the choice of a threshold for BMI, it is useful to briefly recall its history (Tables 2 and 6). Weight/height ${ }^{2}\left(\mathrm{~W} / \mathrm{H}^{2}\right)$ was proposed by Quetelet in $1832^{(25)}$, a Belgian mathematician, astronomer and statistician ${ }^{(26)}$, not to define nutritional state but to define the characteristics of 'normal man'. 'Now, if we compare fully developed and regularly built individuals with each other, in order to know the relations that may exist between weight and height, we will find that the weights in developed individuals of different heights are about the same as the squares of the heights ${ }^{{ }^{(25,27)}}$. W/ $\mathrm{H}^{2}$ was called Quetelet's indice. Keys et al. renamed it in 1972 as the $\mathrm{BMI}^{(28)}$. The authors showed, in twelve cohorts from five countries that BMI was related to fat mass, but no more than half of the total variance in fat mass was accounted for by the regression of fat mass on BMI. Durnin et al. ${ }^{(29)}$ showed that among 6000 healthy and fit young men (5000) and women (1000) in the British Army, the percentage of fat was $16 \cdot 6-21 \cdot 1$ and $27 \cdot 2-29 \cdot 8$, respectively. In fact, BMI includes both fat and lean tissue. In terms of body size, women's bodies have a higher percentage of fat and a lower muscle mass than men's(30) and women's urinary creatinine size index, a 
Table 8. Assessment of the severity of undernutrition in adults aged 18-69 years*

\author{
Criteria for moderate undernutrition (one is sufficient) \\ $17<\mathrm{BMl}<18.5 \mathrm{~kg} / \mathrm{m}^{2}$ \\ weight loss $\geq 5 \%$ in 1 month or $\geq 10 \%$ in 6 months or $\geq 10 \%$ compared with the usual weight before the start of the disease \\ albuminaemia $>30 \mathrm{~g} / \mathrm{l}$ and $<35 \mathrm{~g} / \mathrm{l}$ (immunonephelometry or immunoturbidimetry) \\ Criteria for severe undernutrition (one is sufficient) \\ $\mathrm{BMI} \leq 17 \mathrm{~kg} / \mathrm{m}^{2}$ \\ weight loss $\geq 10 \%$ in 1 month or $\geq 15 \%$ in 6 months or $\geq 15 \%$ compared with the usual weight before the start of the disease \\ albuminaemia $\leq 30 \mathrm{~g} / \mathrm{l}$ (immunonephelometry or immunoturbidimetry)
}

* When a single criterion for severe undernutrition is observed simultaneously with one or more criteria for moderate undernutrition, a diagnosis of severe undernutrition is recommended.

Table 9 Monitoring of the change of nutritional status

Monitoring the change of nutritional status and adapting the management of an undernourished adult patient.

It is recommended to adapt the nutritional management of an undernourished patient according to the level of severity, paying particular attention to the prevention of refeeding syndrome.

In outpatient care, it is recommended that the nutritional status of an undernourished patient be systematically assessed within 3 months of the last assessment.

In the case of hospitalisation, it is recommended that the nutritional status of an undernourished patient be reassessed at least once a week. In follow-up consultations after hospitalisation, particularly in the case of long-term illness, it is recommended that the nutritional status of an undernourished patient be systematically reassessed.

Monitoring the nutritional status and adapting the management of a non-undernourished adult patient, but with a disease (i.e., at risk of malnutrition)

In ambulatory care, it is recommended that the nutritional status of the patient be reassessed at each consultation.

In the case of inpatient care, it is recommended to reassess the nutritional status of a non-undernourished patient on admission.

biomarker of muscle mass, is lower than men's ${ }^{(31)}$. During famine, in the absence of disease, both adipose tissue and lean tissue (muscle) are used as fuel, but the proportion of lean tissue lost depends on the amount of fat stored ${ }^{(32)}$ : the more adipose tissue mass, the lower the loss of lean tissue ${ }^{(33)}$. The preferential loss of lean tissue is the determining factor in an individual's survival at low body weight. During the course of a disease, not only does muscle mass begin to decrease but there is also an increase in muscle fatigability ${ }^{(34)}$. Muscle strength and endurance can be assessed simply by measuring the strength and durability of the grip $^{(35)}$.

The lower limit of $18.5 \mathrm{~kg} / \mathrm{m}^{2}$ was defined in the report of a working group of the International Food Energy Consultative Group sponsored by the United Nations University and the Subcommittee on Nutrition of the United Nations System, published in 1988 by James et al. ${ }^{(36)}$. Based on data for normal males and females, they concluded that the upper limit for the diagnosis of diagnosis of chronic energy deficiency (CED) should be $18.5 \mathrm{~kg} / \mathrm{m}^{2}$ because a BMI $>18.5 \mathrm{~kg} / \mathrm{m}^{2}$ was consistent with good health in both male soldiers and normal females on the basis of data from Durnin et al. ${ }^{(29)}$ for the healthy population and data from healthy adults in the Third World. The WHO report ${ }^{(37))}$ used the average BMI for British Army men aged $25-40$ years of $24.6 \mathrm{~kg} / \mathrm{m}^{2}$ and of $22.7 \mathrm{~kg} / \mathrm{m}^{2}$ for women aged $25-35$ years $^{(29)}$ and took -2 SD as the threshold for the lower limit of an acceptable range, so that the weighted average lower limit was 18.5 for men and 17.6 for women. In most groups of adults living in low-income countries identified by Eveleth \& Tanner ${ }^{(38)}$, the mean BMI was between 19 and $21 \mathrm{~kg} / \mathrm{m}^{2}$. Based on these data, James et al. ${ }^{(36)}$ finally proposed three thresholds at 16 , 17 , and 18.5 , such that a BMI $\geq 18.5 \mathrm{~kg} / \mathrm{m}^{2}$ was considered normal (non-CED), $17 \cdot 0-18 \cdot 4 \mathrm{~kg} / \mathrm{m}^{2}$ was classified as CED grade I,
$16 \cdot 0-16 \cdot 9 \mathrm{~kg} / \mathrm{m}^{2}$ was classified as CED grade II, and $<16 \cdot 0 \mathrm{~kg} / \mathrm{m}^{2}$ as CED grade III. This classification was approved by a meeting of the IDECG in 1992 $2^{(39)}$, and then by the WHO Expert Committee on Physical Status in 1993, but CED was renamed 'thinness'(40). The report states 'a BMI below 16 is known to be associated with a markedly increased risk of ill-health, poor physical performance, lethargy and even death, so this cut-off point has validity as an extreme limit. Moreover, BMI below $17 \mathrm{~kg} / \mathrm{m}^{2}$ has been linked with a clear-cut increase in illness in adults studied in three continents and is therefore a further reasonable value to choose as a cut-off point for moderate risk. The proposal of a single cut-off point of $18.5 \mathrm{~kg} / \mathrm{m}^{2}$ for specified mild deficiency in both sexes has less experimental support, but seems a reasonable value to use pending further comprehensive studies'. The current undernutrition threshold proposed by the WHO is 18.5 (http://apps.who.int/bmi/index.jsp?introPage= intro_3.html). This threshold is also recommended in France for adults under 70 years of age by the National Nutrition and Health Program (in French: Programme National Nutrition Santé) (http://www.sante.gouv.fr/IMG/pdf/brochure_denut rition.pdf), by the decree of November 9, 2009 for the management of enteral nutrition at home (http://textes.droit.org/JORF/ 2010/02/24/0046/0033/) and for coverage by French national health insurance in adults under 70 years old. (https://www. legifrance.gouv.fr/affichTexte.do?cidTexte=JORFT

\section{EXT000021394117\&categorieLien=id).}

In addition, with regard to children, in 2007, the IOTF established thresholds for defining 'thinness' in six countries (Brazil, the UK, Hong Kong, the Netherlands, Singapore and the USA), with a total of 97876 boys and 94851 girls aged $0-25$ years measured in the years 1968-1993 $3^{(19)}$. These were equivalent thresholds for underweight, based on the WHO definition of underweight in 
adults, which corresponds to a BMI of $18.5 \mathrm{~kg} / \mathrm{m}^{2}$ (level 1 underweight), $17 \mathrm{~kg} / \mathrm{m}^{2}$ (level 2 underweight) or $16 \mathrm{~kg} / \mathrm{m}^{2}$ (level 3 underweight) at age 18 years. Percentile curves were plotted to cross the threshold of BMI 17 to 18 years of age. The resulting curves were averaged to provide age- and sex-specific threshold points from 2 to 18 years of age. Similar threshold points were derived based on BMI 16 and $18.5 \mathrm{~kg} / \mathrm{m}^{2}$ at 18 years of age, together providing definitions of thinness levels 1, 2 and 3 for children and adolescents, consistent with WHO definitions for adults. For children under 2 years of age, WHO standards for growth curves from birth to 5 years of age were established in $2006^{(41)}$ and are recommended for use in all countries ${ }^{(42)}$. However, a systematic study ${ }^{(43)}$ showed that these growth curves were imperfectly calibrated with the growth of contemporary children in many countries, including France. In 2019, new growth curves for French children were established from 238102 children (1 458468 height measurements and 1690340 weight measurements), using a 'big-data' approach ${ }^{(44)}$, and from these data, updated BMI curves were established for girls ${ }^{(45)}$ and boys ${ }^{(46)}$ respectively.

\section{Mortality is increased when BMI is $<18.5 \mathrm{~kg} / \mathrm{m}^{2}$}

Mortality has been repeatedly shown to increase significantly in people with a $\mathrm{BMI}<18.5 \mathrm{~kg} / \mathrm{m}^{2}$. Calle et al. ${ }^{(47)}$ studied the relationship between BMI and all-cause deaths in a prospective American cohort of 457785 men and 588369 women followed for 14 years. Among white men and women who had never smoked and were disease free at study entry, mortality increased by $26 \%$ and $36 \%$, respectively. Flegal et al. ${ }^{(48)}$ showed from the three national health and nutrition surveys (NHANES I, 19711975; NHANES II, 1976-1980; NHANES III, 1988-1994, to 2000) (571 042 person-years of follow-up), an increase in mortality of $38 \%$ and $130 \%$ among participants aged $25-59$ and 60-69 years, respectively. In a subsequent study using NHANES I, II, III data, the same authors ${ }^{(49)}$ found a 3.6-fold increase in mortality from non-cancer and non-cardiovascular (CV) causes. Jee et al. ${ }^{(50)}$ examined the association between BMI and mortality in a cohort of 1213829 Koreans (12-year follow-up, 82372 deaths from all causes and 48731 deaths due to specific diseases). After adjusting for age, smoking, alcohol consumption, exercise, fasting blood glucose, systolic blood pressure and serum cholesterol, total mortality increased by $51 \%$ in men and $25 \%$ in women for a BMI $<18.5 \mathrm{~kg} / \mathrm{m}^{2}$. He et al, ${ }^{(51)}$ used data from the National Survey of Hypertension in China, including a representative sample of the general Chinese population $\geq 15$ years ( 1239191 person-years of follow-up, mean follow-up time 8.3 years, 20033 deaths). Mortality increased by $47 \%$ among participants with a $\mathrm{BMI}<18.5 \mathrm{~kg} / \mathrm{m}^{2}(\mathrm{RR}=1.47 ; 95 \% \mathrm{CI}: 1 \cdot 42,1.53)$. In a prospective American cohort (Cancer Prevention Study II, 891572 white and 38119 black men and women, 28-year follow-up), Patel et al. ${ }^{(52)}$ found an RR for all-cause deaths associated with low BMI (15-18.5) of 1.25 (95\% CI: 1.08, 1.45) in white men who had never smoked without prevalent disease, but not significantly in black men $(\mathrm{RR}=0 \cdot 78,95 \% \mathrm{CI}: 0 \cdot 28,2 \cdot 13)$. Among white women, the RR was 1.20 (95\% CI: 1.14, 1.26), and among black women it was 1.38 (95\% CI: $1.03,1.85)$. The Global BMI Mortality Collaboration $^{(26)}$, in 2016, conducted a meta-analysis of 239 prospective studies on four continents (10 625411 participants, median follow-up 13.7 years). The main objective was to limit the analysis to healthy, non-smoking individuals and to exclude the first 5-year follow-up in order to limit confounding effects and reverse causality. Underweight (BMI 15.0 to $<18.5 \mathrm{~kg} / \mathrm{m}^{2}$ ) was associated with a $47 \%$ increase in mortality $(\mathrm{RR}=1.47$; $95 \%$ CI: $1.39,1.55)$. Afzal et al. ${ }^{(53)}$ analyzed data from three Danish cohorts (1976-1978, 1991-1994, 2003-2013) followed until the end of 2014 . A BMI $<18.5 \mathrm{~kg} / \mathrm{m}^{2}$ was associated with a $63 \%(\mathrm{RR}=1.63 ; 95 \% \mathrm{CI}: 1.43,1.86), 78 \%(\mathrm{RR}=1.78 ; 95 \%$ CI: $1 \cdot 47,2 \cdot 15)$ and $68 \%(\mathrm{RR}=1 \cdot 68 ; 95 \% \mathrm{CI}: 1 \cdot 35,2 \cdot 08)$ increase in all-cause mortality for the 3 cohorts, respectively.

Thus, all these data in Westerners (white and black) and Asians indicate that a BMI $<18.5 \mathrm{~kg} / \mathrm{m}^{2}$ is associated with excess mortality in both men and women. The higher threshold of $20 \mathrm{~kg} / \mathrm{m}^{2}$ proposed by GLIM experts was chosen on the basis of the average increase in BMI of the entire American adult population over the last few years. The GLIM report ${ }^{(15)}$, which is intended for the world community, states that 'the experience of the current USA population shows that people are often overweight or obese and that they would have to lose a lot of weight before being assigned a low BMI. However, there is no reference cited to support the claim that mortality is increased for a BMI $<20 \mathrm{~kg} / \mathrm{m}^{2}$ in people under 70 years of age. This other sentence in the GLIM recommendations 'However, further research is needed to obtain consensus baseline BMI data for Asian populations in clinical settings' indicates that if 20 is proposed, it cannot be for the global nutrition community. We have cited several studies showing clearly that a $\mathrm{BMI}<18.5 \mathrm{~kg} / \mathrm{m}^{2}$ is associated with mortality in the same way in Westerners as in Asians. For all these reasons, we have found that a threshold of 18.5 as a phenotypic criterion is the most appropriate.

Since BMI is strongly related to FM and does not necessarily correlate with muscle mass, an assessment of muscle mass or function requires further measurement. Two muscle-specific metabolites were evaluated as potential measures of body muscle: creatinine and 3-methylhistidine. With respect to creatinine, Heymsfield et al. ${ }^{(54)}$ concluded that urinary creatinine had inter- and intra-individual variability and that a defined value for creatinine equivalence with a range of kg muscle mass per $\mathrm{g}$ urinary creatinine from 17 to 22 was missing. As for urinary 3-methylhistidine, which mainly reflects protein renewal and not muscle mass, it requires a totally meat-free diet for 3 days and sedentary activity; the coefficient of variation of collection is 5 to $10 \%$ and it requires a stable state of protein renewal, which is not obtained in case of famine or catabolic diseases. The methods/techniques currently proposed to assess muscle mass/function are: grip strength (dynamometer), walking speed, muscle surface area index in L3 (CT-scan, MRI-scan), muscle mass index (impedance measurement) and appendix muscle mass (DEXA). Reference values have been proposed ${ }^{(55-57)}$, and research is underway to better delineate these references.

\section{Why is weight loss important for diagnosis of undernutrition?}

Andres et al. ${ }^{(58)}$, in 1993, reviewed thirteen studies and concluded that even slight or moderate long-term weight loss was generally 
associated with a high mortality rate (Tables 2 and 6). As reviewed by Wong ${ }^{(59)}$, several other studies showed that involuntary weight loss was associated with a mortality rate of $16-38 \%{ }^{(60-65)}$. Allison et al. ${ }^{(66)}$, in 1999, compared the effect of weight loss in two cohorts: the Tecumseh Community Health Study (1890 subjects; 321 deaths within 16 years of follow-up) and the Framingham Cardiac Study (2731 subjects; 507 deaths within 8 years of follow-up). They found that each SD of weight loss $(4.6 \mathrm{~kg}$ in Tecumseh, $6.7 \mathrm{~kg}$ in Framingham) increased mortality by $29 \%$ and $39 \%$, respectively. In contrast, each SD of fat loss $(10.0 \mathrm{~mm}$ in Tecumseh, $4.8 \mathrm{~mm}$ in Framingham) reduced the risk of mortality by $15 \%$ and $17 \%$, respectively. Bullock et al. ${ }^{(67)}$ conducted a meta-analysis on markers of undernutrition and clinical outcomes in elderly cancer patients. One study found that $5 \%$ weight loss in 3 months was associated with early post-operative death within 3 months; 2 studies found an association between weight loss and mortality, where weight loss between 5 and $10 \%,>10 \%,>3 \mathrm{~kg}$ or unknown weight loss was associated with 1 year mortality. Weight loss in the last 6 months was also associated with mortality. DeWys et al. ${ }^{(68)}$ found that weight loss was also a predictor of reduced survival by approximately $50 \%$ in 3047 cancer patients, depending on tumor type, grade and stage. A $5 \%$ decrease in weight was sufficient to decrease survival. Similarly, in patients with respiratory disease, weight loss is associated with increased mortality and disability ${ }^{(69)}$. In patients with small cell lung cancer, among 25 factors, weight loss was the fourth most associated with decreased survival ${ }^{(70)}$.

Losing weight is not always harmful. Losing fat is sometimes desirable, but losing weight becomes harmful when weight loss is mainly FFM. Since FFM contains water (about $80 \%$ ), and assuming that it is composed mainly of proteins, $1 \mathrm{~g}$ (dry weight) of protein actually weighs $5 \mathrm{~g}$ in normally hydrated tissue. Thus, $1 \mathrm{~g}$ of FFM represents about $1 \mathrm{kcal}$, while $1 \mathrm{~g}$ of fat mass (which does not contain water) contains $9 \mathrm{kcal}$. Therefore, $1800 \mathrm{kcal}$ corresponds to $200 \mathrm{~g}$ of fat or $1.8 \mathrm{~kg}$ of muscle. In real life, when a patient loses weight, she or he consumes both fat and non-fat mass, but in varying proportions depending on the situation. For a given energy deficit, the faster the rate of weight loss, the greater the proportion of muscle consumed. Thus, the speed of weight loss is recognised as a phenotypic criterion of undernutrition by many consensuses, including the GLIM. This makes it possible to diagnose undernutrition in overweight and obese patients. The thresholds we have chosen are different from those of the GLIM (GLIM has chosen a $5 \%$ weight loss in 6 months, whereas we have chosen $10 \%$ for the same period of time), but close to those previously published such as the Subjective Global Assessment (SGA) ${ }^{(71)}$, the Malnutrition Universal Screening Tool (MUST) ${ }^{(72)}$ or the Nutritional Risk Screening 2002 (NRS-2002) ${ }^{(73)}$. For a person weighing $80 \mathrm{~kg}$, for example, losing $4 \mathrm{~kg}(5 \%)$ in 6 months corresponds to an energy deficit of $36000 \mathrm{kcal}$ (200 kcal per day) if she or he consumes $4 \mathrm{~kg}$ of fat. Theoretically, such a weight loss can occur without necessarily affecting muscle mass. This is much less likely when the patient loses $10 \%$ of their body weight during the same period. In other words, we have chosen a threshold that is less sensitive but more specific to a decrease in muscle mass.

In many consensuses/recommendations, weight loss must be unintentional to be considered as a diagnosis criterion for undernutrition. However, this remains poorly supported by scientific evidence. Indeed, even if loss of weight is intentional (e.g., after bariatric surgery), loss of muscle mass remains harmful. We understand that inducing undernutrition by trying to treat obesity is a problem for many colleagues, but while weight loss is sometimes desired, the loss of lean mass is never voluntary and that of muscle mass not desirable. This is why, based on pathophysiology rather than on the treatment of obesity, we decided that any weight loss corresponding to the thresholds we had chosen should be considered as a phenotypical criterion of undernutrition, even in the case of voluntary weight loss.

Of course, depending on the clinical situation and the expected benefit of voluntary weight loss, permissive undernutrition can be tolerated. This is particularly the case in young adults. But it seemed important to us to stress that any voluntary weight loss must be the subject of a risk benefit analysis and that priority should be given to slow and continuous weight loss associated with physical activity.

\section{Why is decrease in food intake important too?}

In adults, the dominant cause of decreased body weight is a decrease in food consumption, caused either by the unavailability of sufficient food to meet energy requirements or by anorexia or any other cause limiting the patient's ability to eat (Tables 2 and 6). For example, in elderly patients with cancer, a recent meta-analysis found that decreased food consumption was associated with mortality (OR $2.1 ; P<0 \cdot 00001)^{(67)}$. Assessment of dietary intake is therefore of major importance in the evaluation of nutritional status. In patients with small cell lung cancer, $97 \%$ experienced a loss of appetite $^{(74)}$. Among twenty-five factors, loss of appetite was the sixth most common factor associated with decreased survival ${ }^{(67)}$.

\section{What about albumin?}

In people who have a low caloric intake, such as patients with anorexia nervosa or hunger strikers, with no somatic disease, serum albumin levels remain normal even at very low BMIs ${ }^{(75)}$ (Table 8). In addition, for many years, it has been shown that plasma albumin decreases in inflammatory states such as injuries when the acute phase reaction is activated. This decrease is the result of both decreased synthesis and increased catabolism ${ }^{(76)}$. Low plasma albumin levels have been shown to be a prognostic factor for increased mortality or poor outcomes in many diseases such as end-stage renal failure, cancer and surgery. Mortality and poor prognosis are inversely related to plasma albumin levels ${ }^{(77-82)}$. Thus, albumin should not be considered as a marker of undernutrition but as a marker of severity. Since albumin is a linear prognostic factor (the lower it is, the worse the prognosis), there is no clearly defined cut-off. We have retained the value of $30 \mathrm{~g} / \mathrm{l}$ which corresponds to a curvature of the albumin/prognosis relationship.

\section{We wanted the criteria to be as consistent as possible} between children and adults and as easy as possible to use

In order to achieve this objective, it was necessary that an expert committee comprising specialists in adult and paediatric medicine formulate the recommendations for adults and children at the 
same time. In addition, we wanted the criteria to be easy to use and understand by non-nutrition health professionals, so that we would not have to propose too many criteria. Finally, we felt it was very necessary to take into account the new and very relevant approach used by both the GLIM consensus and the Academy of Nutrition and Dietetics/ASPEN consensus statement. This very interesting approach mixes phenotypic and aetiological criteria and highlights the importance of assessing muscle mass/ function. It is clear that the aim of the new French recommendations was not to be orthogonal to the two recommendations cited, which were intended for the world nutrition community, but to be applicable to the French community, which only had at its disposal dated recommendations that no longer appeared relevant for adults, and no recommendations for children. At the same time, we would also like to draw modest attention to some limitations we found in these adult and paediatric recommendations aiming to be used by the worldwide nutrition community.

\section{Conclusion}

These new French recommendations for the diagnosis of undernutrition for people under 70 years of age include several original features. They integrate the proposals of recent international recommendations combining aetiologic criteria with phenotypic criteria, but for the first time, they have been deliberately established to allow a concordance of adult and paediatric criteria. Regarding BMI curves in children, they propose to use both IOTF for children $>2$ years and new French BMI curves for children $<2$ years of age, so that the recommendations are applicable to children from 0 to 18 years of age. The WHO threshold of 18.5 for BMI proposed by the WHO was kept as phenotypic criteria because, among others things, epidemiological data in many populations including Asians showed an increased mortality for a BMI under that threshold. These recommendations will be revised every 3 to 5 years in order to take into account any new data likely to change the criteria and their applicability. Lastly, recommendations for people aged $\geq 70$ years are ongoing and will be available in 2021 .

\section{Acknowledgements}

We thank Mrs Elizabeth Mullen for revision of English language of this manuscript. Elisabeth Mullen reviewed and edited English language. Emmanuelle Blondet searched bibliography resources.

J. D., A. P. and E. F. coordinated the recommendations; J. C. D. and F. J. analysed the bibliography for adults and proposed recommendations for adults; B. D. and E. M. analysed the bibliography for children and proposed recommendations for children; A. P. made the synthesis of proposed children and adults recommendations; HAS Working group made comments about proposed Recommendations; J. D. wrote the paper; J. D. had primary responsibility for final content. All authors have red and approved the final manuscript.

All authors have no conflict of interest related to this manuscript.

\section{References}

1. Norman K, Pichard C, Lochs H, et al. (2008) Prognostic impact of disease-related undernutrition. Clin Nutr 27, 5-15.

2. American Academy of Pediatrics Committee on Nutrition (2013) Failure to thrive. In Pediatric Nutrition, pp. 663-700 [Kleinman RE \& Greer FR, editors]. Elk Grove Village, IL: American Academy of Pediatrics.

3. Cederholm T \& Jensen GL (2017) To create a consensus on undernutrition diagnostic criteria. JPEN J Parenter Enteral Nutr 41, 311-314.

4. Allison SP (2000) Undernutrition, disease, and outcome. Nutrition 16, 590-593.

5. Williams CD (1935) Kwashiorkor: a nutritional disease of children associated with a maize diet. Lancet 2, 1151-1152.

6. Williams CD (1933) A nutritional disease of childhood associated with a maize diet. Arch Dis Child 8, 423-433.

7. Waterlow JC (1972) Classification and definition of proteincalorie undernutrition. Br Med J 3, 566-569.

8. Gopalan C (1968) Calorie Deficiencies and Protein Deficiencies. London: J \& A Churchill.

9. Briend A (2014) Kwashiorkor: still an enigma - the search must go on. CMAM Forum Technical Brief. https://www.ennonline. net/kwashiorkorstillanenigma (accessed March 2021).

10. Morley JE, Thomas DR \& Wilson MMG (2006) Cachexia: pathophysiology and clinical relevance Am J Clin Nutr 83, 735-743.

11. Vigano AAL, Morais JA, Ciutto L, et al. (2017) Use of routinely available clinical, nutritional, and functional criteria to classify cachexia in advanced cancer patients. Clin Nutr 36, 1378-1390.

12. Okoshi MP, Capalbo RV \& Romeiro FG (2017) Cardiac Cachexia: perspectives for prevention and treatment. Arc Bras Cardiol 108, 74-80.

13. Lorenzo-López L, Maseda A, de Labra C, et al. (2017) Nutritional determinants of frailty in older adults: a systematic review. $B M C$ Geriatr 17, 108.

14. Ligthart-Melis GC, Luiking YC, Kakourou A, et al. (2020) Frailty, sarcopenia, and malnutrition frequently (co-)occur in hospitalized older adults: a systematic review and meta-analysis. $J \mathrm{Am}$ Med Dir Assoc 21, 1216-1228.

15. Cederholm T, Jensen GL, Correia MITD, et al. (2019) GLIM Core Leadership Committee; GLIM Working Group. GLIM criteria for the diagnosis of undernutrition - a consensus report from the global clinical nutrition community. Clin Nutr 38, 1-9.

16. Young JA (1979) Height, weight, and health: an anthropometric study of human growth in nineteenth-century American medicine. Bull History Med 53, 214-243.

17. WHO (1999) Management of Severe Undernutrition: a Manual for Physicians and other Senior Health Workers. Geneva: World Health Organization.

18. Centers for Disease Control and Prevention Growth charts (2000) CDC growth charts for the United States. http://www. cdc.gov/growthcharts/ (accessed November 2020).

19. Cole TJ, Flegal KM \& Nicholls D (2007) Body mass index cut offs to define thinness in children and adolescents: international survey. BMJ 335, 194-202.

20. Joosten KFM \& Hulst JM (2008) Prevalence of undernutrition in pediatric hospital patients. Curr Opin Pediatr 20, 590-596.

21. Mehta NM, Corkins MR, Lyman B, et al. (2013) American Society for Parenteral and Enteral Nutrition Board of Directors. Defining pediatric undernutrition: a paradigm shift toward etiology-related definitions. JPEN J Parenter Enteral Nutr 37, 460-481.

22. Becker P, Carney LN, Corkins MR, et al. (2015) Academy of Nutrition and Dietetics; American Society for Parenteral and Enteral Nutrition. Consensus statement of the Academy of Nutrition and Dietetics/American Society for Parenteral and Enteral Nutrition: indicators recommended for the 
identification and documentation of pediatric undernutrition (undernutrition). Nutr Clin Pract 30, 147-161.

23. HAUTE AUTORITE DE SANTE (2003) Evaluation diagnostique de la dénutrition protéino-énergétique des adultes hospitalisés. https://www.has-sante.fr/portail/jcms/c_432199/ $\mathrm{fr} /$ evaluation-diagnostique-de-la-denutrition-proteino-energeti que-des-adultes-hospitalises (accessed November 2020).

24. HAUTE AUTORITE DE SANTE (2007) Stratégie de prise en charge en cas de dénutrition protéino-énergétique chez la personne âgée. https://www.has-sante.fr/portail/jcms/c_ 546549/fr/strategie-de-prise-en-charge-en-cas-de-denutrition-pro teino-energetique-chez-la-personne-agee (accessed November 2020).

25. Quetelet A (1832) Recherches sur le poids de l'homme aux différents âges. In. Nouveaux Mémoires de l'Académie Royale des Sciences et Belles Lettres de Bruxelles tome VII: pp 683-730, 1832 https://gdz.sub.unigoettingen.de/id/ PPN129323640_0007?tify=\{\%22pages\%22:(694,695),\%22view\% 22:\%22\%22\} (accessed November 2020).

26. Global BMI Mortality Collaboration, Di Angelantonio E, Bhupathiraju SN, et al. (2016) Body-mass index and allcause mortality: individual-participant-data meta-analysis of 239 prospective studies in four continents. Lancet 388, 776-786.

27. Eknoyan G (2008) Adolphe Quetelet (1796-1874), the average man and indices of obesity. Nephrol Dial Transplant 23, $47-51$

28. Keys A, Fidanza F, Karvonen MJ, et al. (1972) Indices of relative weight and obesity. J Chronic Dis 25, 329-343.

29. Durnin JVGA, McKay FC \& Webster CI (1984) A new method of assessing fatness and desirable weight for use in the Armed Services. London: Unrestricted report to Army Department, Ministry of Defence.

30. Kirchengast S (2010) Gender Differences in Body Composition from Childhood to Old Age: an Evolutionary Point of View. J Life Sci 2, 1-10.

31. Mendez J \& Buskirk ER (1971) Creatinine-height index. Am J Clin Nutr 24, 385-386

32. Forbes GB (1987) Lean body mass-body fat interrelationship in humans. Nutr Rev 45, 225-231.

33. Ferro-Luzzi A, Branca F \& Pastore G (1994) Body mass index defines the risk of seasonal energy stress in the Third World. Eur J Clin Nutr 48, S165-S178.

34. Lopes J, Russell DM, Whitwell J, et al. (1982) Skeletal muscle function in malnutrition. Am J Clin Nutr 36, 602-610.

35. Rijk JM, Roos PR, Deckx L, et al. (2016) Prognostic value of handgrip strength in people aged 60 years and older: a systematic review and meta-analysis. Geriatr Gerontol Int 16, 5-20.

36. James WP, Ferro-Luzzi A \& Waterlow JC (1988) Definition of chronic energy deficiency in adults. Report of a working party of the International Dietary Energy Consultative Group. Eur J Clin Nutr 42, 969-981.

37. (1986) Use and interpretation of anthropometric indicators of nutritional status Bulletin of the World Health Organization 1986 64, 929-941. https://apps.who.int/iris/handle/10665/ 46968 (accessed November 2020).

38. Eveleth PB \& Tanner JM (1976) Worldwide Variation in Human Growth. London: Cambridge University Press.

39. The functional significance of low body mass index (BMI) (1994) Proceedings of an IDECG workshop. Rome, Italy, 4-6 November 1992. Eur J Clin Nutr 48, S1-S202.

40. WHO Expert Committee on Physical Status: the Use and Interpretation of Anthropometry (1993: Geneva, Switzerland) \& World Health Organization (1995) Physical status: the use of and interpretation of anthropometry, report of a WHO expert committee. World Health Organization. https:/apps.who.int/ iris/handle/10665/37003 (accessed November 2020).

41. WHO Multicentre Growth Reference Study Group (2006) WHO Child Growth Standards based on length/height, weight and age. Acta Paediatr Suppl 450, 76-85.

42. de Onis M, Onyango A, Borghi E, et al. (2012) WHO Multicentre Growth Reference Study Group. Worldwide implementation of the WHO Child Growth Standards. Public Health Nutr 15, 1603-1610.

43. Scherdel P, Dunkel L, van Dommelen P, et al. (2016) Growth monitoring as an early detection tool: a systematic review. Lancet Diabetes Endocrinol 4, 447-456.

44. The Lancet (2020) Measuring growth: descriptive or prescriptive. https://www.thelancet.com/journals/landig/article/PIIS25897500(19)30149-9/fulltext (accessed November 2020).

45. https://cress-umr1153.fr/wp-content/uploads/2018/03/CourbesIMC-filles-1-18-ans-AFPA-CRESS-Inserm-CGM-2018.pdf (accessed November 2020).

46. https://cress-umr1153.fr/wp-content/uploads/2018/03/CourbesIMC-garcons-1-18-ans-AFPA-CRESS-Inserm-CGM-2018.pdf (accessed November 2020).

47. Calle EE, Thun MJ, Petrelli JM, et al. (1999) Body-mass index and mortality in a prospective cohort of U.S. adults. N Engl J Med 341, 1097-1105.

48. Flegal KM, Graubard BI, Williamson DF, et al. (2005) Excess deaths associated with underweight, overweight, and obesity. JAMA 293, 1861-1867.

49. Flegal KM, Graubard BI, Williamson DF, et al. (2007) Causespecific excess deaths associated with underweight, overweight, and obesity. JAMA 298, 2028-2037.

50. Jee SH, Sull JW, Park J, et al. (2006) Body-mass index and mortality in Korean men and women. N Engl J Med 355 , 779-787.

51. He J, Gu D, Wu X, et al. (2005) Major causes of death among men and women in China. N Engl J Med 353, 1124-1134.

52. Patel AV, Hildebrand JS \& Gapstur SM (2014) Body mass index and all-cause mortality in a large prospective cohort of white and black U.S. Adults. PLoS One 9, e109153.

53. Afzal S, Tybjærg-Hansen A, Jensen GB, et al. (2016) Change in body mass index associated with lowest mortality in Denmark, 1976-2013. JAMA 315, 1989-1996.

54. Heymsfield SB, Arteaga C, McManus C, et al. (1983) Measurement of muscle mass in humans: validity of the 24-hour urinary creatinine method. Am J Clin Nutr 37, 478-494.

55. Boshier PR, Heneghan R, Markar SR, et al. (2018) Assessment of body composition and sarcopenia in patients with esophageal cancer: a systematic review and meta-analysis. Dis Esophagus 31, 1-11.

56. Cederholm T, Bosaeus I, Barazzoni R, et al. (2015) Diagnostic criteria for undernutrition: an ESPEN Consensus Statement. Clin Nutr 34, 335-340

57. Lee K, Shin Y, Huh J, et al. (2019) Recent issues on body composition imaging for sarcopenia evaluation. Korean J Radiol $\mathbf{2 0}$, 205-217.

58. Andres R, Muller DC \& Sorkin JD (1993) Long-term effects of change in body weight on all-cause mortality. A review. Ann Intern Med 119, 737-743.

59. Wong CJ (2014) Involuntary weight loss. Med Clin North Am 98, 625-643.

60. Wallace JI, Schwartz RS, LaCroix AZ, et al. (1995) Involuntary weight loss in older outpatients: incidence and clinical significance. I Am Geriatr 43, 29-37.

61. Bilbao-Garay J, Barba R, Losa-Garcia JE, et al. (2002) Assessing clinical probability of organic disease in patients 
with involuntary weight loss: a simple score. Eur J Intern Med 13, 240-245.

62. Marton KI, Sox HC \& Krupp JR (1981) Involuntary weight loss: diagnostic and prognostic significance. Ann Intern Med $\mathbf{9 5}$, 568-574.

63. Lankisch PG, Gerzmann M, Gerzmann JF, et al. (2001) Unintentional weight loss: diagnosis and prognosis. The first prospective follow-up study from a secondary referral centre. J Intern Med 249, 41-46.

64. Metalidis C, Knockaert DC, Bobbaers H, et al. (2008) Involuntary weight loss. Does a negative baseline evaluation provide adequate reassurance? Eur J Intern Med 19, 345-349.

65. Rabinovitz M, Pitlik SD, Leifer M, et al. (1986) Unintentional weight loss: a retrospective analysis of 154 cases. Arch Intern Med 146, 186-187.

66. Allison DB, Zannolli R, Faith MS, et al. (1999) Weight loss increases and fat loss decreases all-cause mortality rate: results from two independent cohort studies. Int J Obes Relat Metab Disord 23, 603-611.

67. Bullock AF, Greenley SL, McKenzie GAG, et al. (2020) Relationship between markers of undernutrition and clinical outcomes in older adults with cancer: systematic review, narrative synthesis and meta-analysis. EurJ Clin Nutr 74, 1519-1535.

68. Dewys WD, Begg C, Lavin PT, et al. (1980) Prognostic effect of weight loss prior to chemotherapy in cancer patients. Eastern Cooperative Oncol Group Am J Med 69, 491-497.

69. Gea J, Sancho-Muñoz A \& Chalela R (2018) Nutritional status and muscle dysfunction in chronic respiratory diseases: stable phase versus acute exacerbations. J Thorac Dis 10, S1332S1354.

70. Stanley KE (1980) Prognostic factors for survival in patients with inoperable lung cancer. J Natl Cancer Inst 65, 25-32.

71. Detsky AS, McLaughlin JR, Baker JP, et al. (1987) What is subjective global assessment of nutritional status? JPEN J Parenter Enteral Nutr 11, 8-13.
72. Stratton RJ, Hackston A, Longmore D, et al. (2004) Malnutrition in hospital outpatients and inpatients: prevalence, concurrent validity and ease of use of the 'malnutrition universal screening tool' ('MUST') for adults. Br J Nutr $\mathbf{9 2}, 799-808$.

73. Kondrup J, Rasmussen HH, Hamberg O, et al. (2003) Nutritional risk screening (NRS 2002): a new method based on an analysis of controlled clinical trials. Clin Nutr 22, 321-336.

74. Iyer S, Roughley A, Rider A, et al. (2014) The symptom burden of non-small cell lung cancer in the USA: a real-world cross-sectional study. Support Care Cancer 22, 181-187.

75. Lee JL, Oh ES, Lee RW, et al. (2015) Serum albumin and prealbumin in calorically restricted, nondiseased individuals: a systematic review. Am J Med 128, 1023.e1-1023.e22.

76. Fleck A (1989) Clinical and nutritional aspects of changes in acute-phase proteins during inflammation. Proc Nutr Soc $\mathbf{4 8}$, $347-354$.

77. Foley RN, Parfrey PS, Harnett JD, et al. (1996) Hypoalbuminemia, cardiac morbidity, and mortality in endstage renal disease. J Am Soc Nephrol 7, 728-736.

78. Gibbs J, Cull W, Henderson W, et al. (1999) Preoperative serum albumin level as a predictor of operative mortality and morbidity: results from the National VA Surgical Risk Study. Arch Surg 134, 36-42.

79. Kudsk KA, Tolley EA, DeWitt RC, et al. (2003) Preoperative albumin and surgical site identify surgical risk for major postoperative complications. JPEN J Parenter Enteral Nutr 27, 1-9.

80. Mehrotra R, Duong U, Jiwakanon S, et al. (2011) Serum albumin as a predictor of mortality in peritoneal dialysis: comparisons with hemodialysis. Am J Kidney Dis 58, 418-428.

81. Mantzorou M, Koutelidakis A, Theocharis S, et al. (2017) Clinical value of nutritional status in cancer: what is its impact and how it affects disease progression and prognosis? Nutr Cancer 69, 1151-1176.

82. Fruchtenicht AV, Poziomyck AK, Kabke GB, et al. (2015) Nutritional risk assessment in critically ill cancer patients: systematic review. Rev Bras Ter Intensiva 27, 274-283. 